\title{
Coupling of an acoustic emissions system to a laboratory torrefaction reactor
}

\author{
Edgar A. Silveira ${ }^{\mathrm{a}, \mathrm{d}, *}$, Marcus Vinícius Girão de Morais ${ }^{\mathrm{a}}$, Patrick Rousset ${ }^{\mathrm{b}, \mathrm{c}}$, \\ Armando Caldeira-Pires ${ }^{\mathrm{a}}$, Anélie Pétrissans ${ }^{\mathrm{d}}$, Luiz Gustavo Oliveira Galvão ${ }^{\mathrm{e}}$ \\ a Mechanical Engineering Department, University of Brasília, Brasília, DF 70910-900, Brazil \\ ${ }^{\mathrm{b}}$ Biowooeb, Univ Montpellier, Cirad, Montpellier, France \\ ' Joint Graduate School of Energy and Environment-Center of Excellence on Energy Technology and Environment-KMUTT, Bangkok 10140, Thailand \\ d Université de Lorraine, Inra, LERMaB, F88000 Epinal, France \\ ${ }^{\mathrm{e}}$ Forest Products Laboratory (LPF), Brazilian Forest Service (SFB), 70818-900, Brazil
}

\section{A R T I C L E I N F O}

\section{Keywords:}

Torrefaction

Eucalyptus grandis

Experimental acoustic analysis

Solid yield

Conversion rate

\begin{abstract}
A B S T R A C T
This article describes the use and characterization of an acoustic system coupled to a torrefaction reactor. The reactor, including phase shift and frequency, was characterized by applying both Lissajous/Hilbert and crossspectrum techniques. Optimum acoustic frequencies were identified and an exploratory torrefaction test combining frequencies and temperatures was performed. The results from dynamic solid yields, conversion rates and temperature profiles showed that acoustic fields may improve torrefaction treatment.
\end{abstract}

\section{Introduction}

Torrefaction as a pre-treatment process involves the slow heating of biomass in an inert environment to a maximum temperature of approximately $300{ }^{\circ} \mathrm{C}$. It converts biomass into a hydrophobic solid product with an increased energy density [1]. Major factors governing chemical reactions in a porous medium include chemical kinetics and heat and mass transfer, which are decisive in many devices of the chemical and energy industries. Given the development of thicker boundary layers by larger-sized biomass particles during torrefaction, some limitations arise from problems related to heat and mass transfer issues [2]. The motivation for this research work came from the potential use of this wood thermal treatment combined with an acoustic system to improve torrefaction treatment.

Thermoacoustic is responsible for some phenomena such as combustion instabilities (self-excited oscillation due to coupling between unsteady heat release and acoustic waves) [3,4], Rijke tubes [5] and thermoacoustic heat engines [6,7].

Some authors have shown relationships between thermal transfers and acoustic waves. [8] discussed the possibility for enhancement of heat transfer between solids and ambient gas by application of powerful acoustic field. Results showed that the heat transfer rate between a preheated wire and ambient gas can be enhanced under the application of sound waves. The heat transfer coefficient increases with the sound strength in both standing and travelling sound waves. In [9] the interaction between a standing wave acoustic field in a duct and a heated section was experimentally examined to enhance the overall convective heat transfer.

However, no work was found where torrefaction was combined with an acoustic field under pyrolysis or oxidative conditions. The assumption is that an acoustic field in a torrefaction reactor modifies the pressure and particles velocities around the wood sample. The combined effect of heat and acoustics could modify the interaction between reactor gaseous environment and wood sample, modifying degradation processes development.

To that end, an acoustic system was applied inside an existing torrefaction reactor [10] and subsequently characterized. Three different methodologies were used in terms of time and frequency domains. This characterization allowed the measurement of the flow rate and acoustic intensity at the exact spot where the sample was in the reactor. These acoustic results were analysed and used to predict which acoustic frequency and intensity produced the ideal conditions for obtaining higher particles velocities around the wood sample.

Finally, a preliminary torrefaction test was performed to observe the coupling effect of temperature and acoustic waves on temperature, solid yield and conversion rate profiles.

\footnotetext{
*Corresponding author at: Mechanical Engineering Department, University of Brasília, Brasília, DF 70910-900, Brazil and Université de Lorraine, Inra, LERMaB, F88000 Epinal, France.

E-mail address: 150101490@aluno.unb.br (E.A. Silveira).
} 


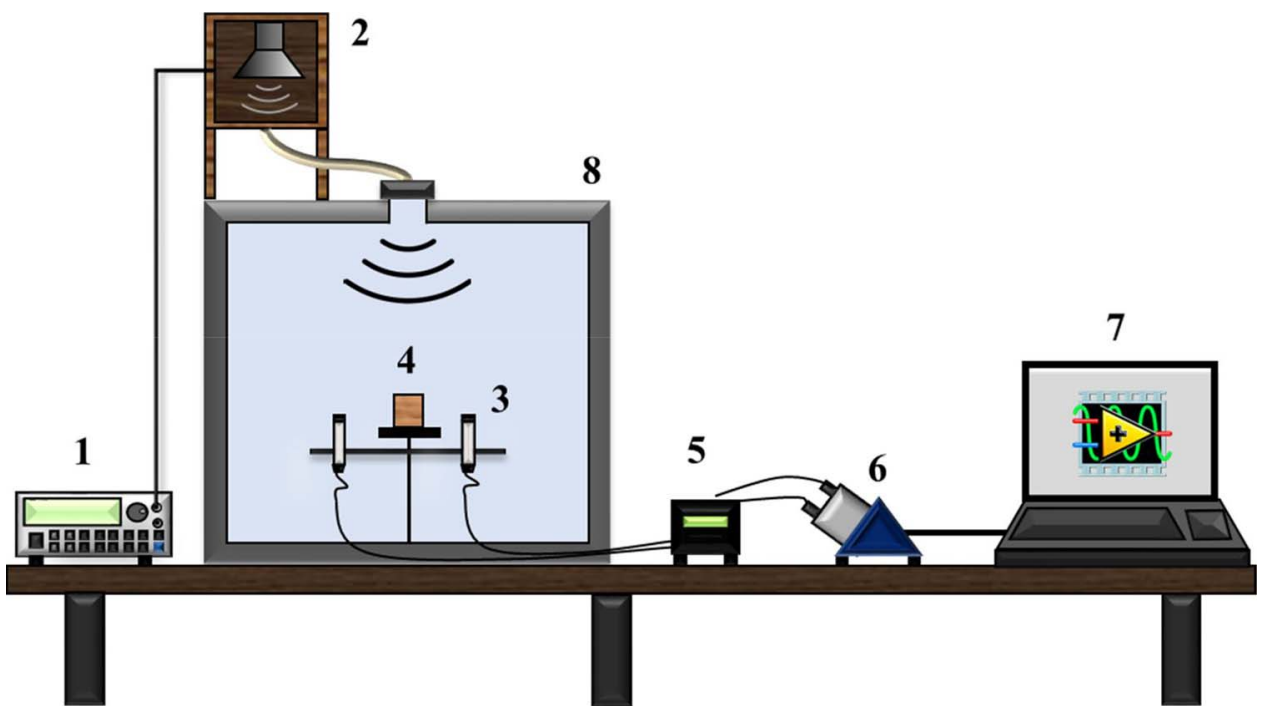

Fig. 1. General scheme of the experimental torrefaction acoustic system. 1) HP 33120A Signal Generator, 2) Selenium D220TI 8 Speaker, 3) Brüel \& Kjær Microphones, 4) Wood sample, 5) Nexus Brüel \& Kjær Conditioner, 6) CompactDAQ NI9174 and NI9234, 7) Computer (Labview Software), 8) Reactor.

\section{Material and methods}

\subsection{Thermoacoustic torrefaction lab-scale reactor}

The acoustic system coupled to the existing reactor [10] is illustrated in Fig. 1.

The acoustic experiment was performed with a humidity of $50 \%$, an average temperature of $24^{\circ} \mathrm{C}$, speed of sound $c=345 \mathrm{~m} \mathrm{~s}^{-1}$ and an air density of $\rho=1.23 \mathrm{~kg} \mathrm{~m}^{-3}$. Within the experimental acoustic system, the desired frequencies were produced by an HP 33120A wave generator with a broadband frequency of $20 \mathrm{~Hz}-20 \mathrm{kHz}$. The acoustic wave was delivered by a Selenium D220TI 8 speaker connected by a flexible duct [11] to the reactor cavity measuring $41 \times 32 \times 40 \mathrm{~cm}$. Different acoustic frequencies produce different excitations of the reactor's cavity, hence a different pressure field. Frequencies were explored within a range of $0-3000 \mathrm{~Hz}$.

The acoustic signals were measured and processed by two Brüel \& Kjær 194537 microphones connected to a Brüel \& Kjær NEXUS amplifier. Data acquisition was performed by a National Instruments CompactDAQ NI9174-NI9234 interfaced by a Labview device.

\subsection{Thermoacoustic torrefaction}

The resulting laboratory-scale reactor used to perform a preliminary torrefaction experiment under acoustic influence is illustrated in Fig. 2. The device involved four subsystems: acoustic (A), heat treatment (B), power and recording (C) and gas feeding (D).

The acoustic subsystem was composed of a wave generator and one speaker connected by a flexible duct to deliver the acoustic wave inside the reactor. Oxygen concentration was controlled by $\mathrm{N}_{2}$ injection. For the heat treatment section, it was composed of a reactor chamber, a support for the wood sample connected to a mass balance (Sartorius $L P 2200 S$ ) with an accuracy of $10^{-3}$ grams, two electric resistances and two type $\mathrm{K}$ special thermocouples (IEC 584-3) with a bead size of $1 \mathrm{~mm}$ and a tolerance value of $1.1{ }^{\circ} \mathrm{C}$ to determine the temperatures of the wood surface and wood core. To control the reactor temperatures and heating rate a programmable PID (proportional-integral-derivative) was utilized based on data from a thermal sensor PT100 placed within the system in the centre of the reactor to record atmosphere temperature. The system provide continues acquisition data with a $100 \mathrm{~Hz}$ sampling rate (e.bloxx A4-1TC Multichannel) recording thermocouples temperature profiles and mass weight during the wood heat treatment.

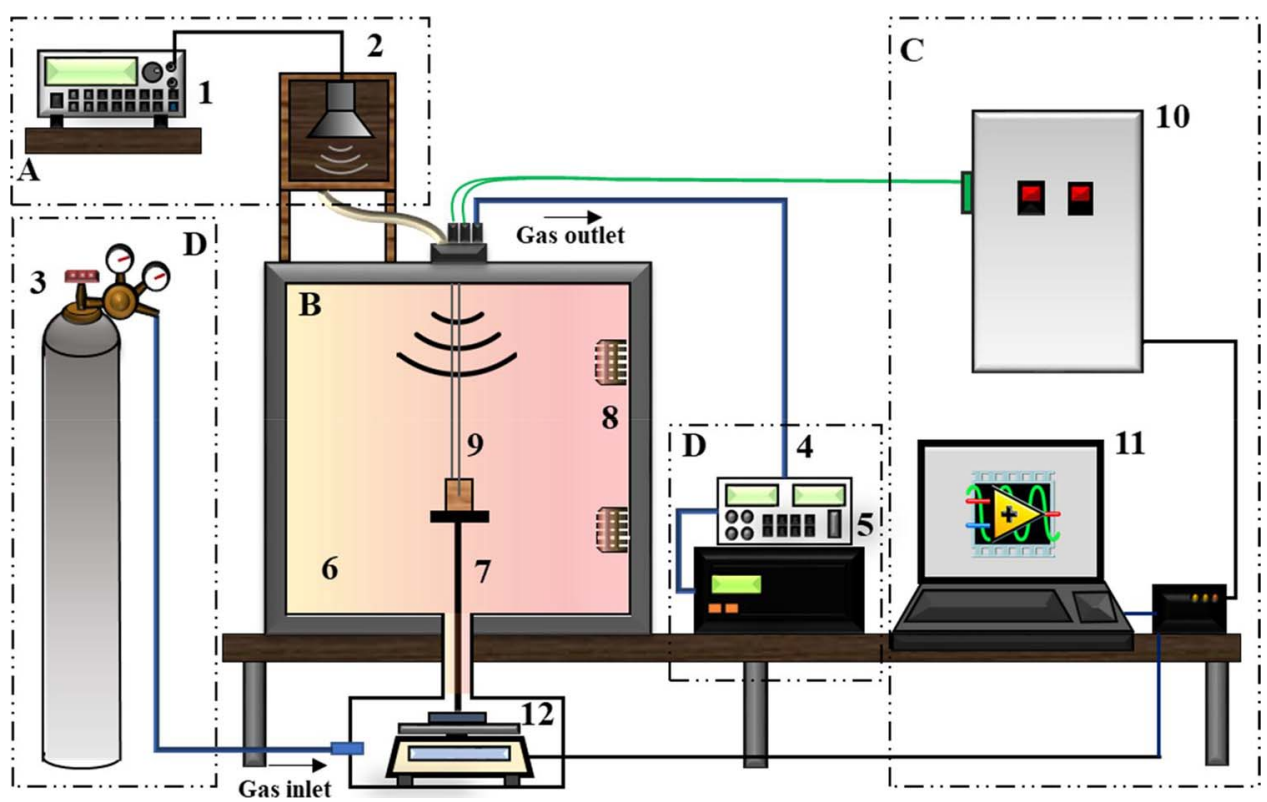

Fig. 2. General diagram of the experimental torrefaction system: 1) Wave generator; 2) Sound speaker 3) $\mathrm{N}_{2}$ cylinder; 4) Gas pump; 5) $\mathrm{O}_{2}$ control; 6) Reactor chamber; 7) Wood sample support; 8) Electric resistances for convection heating; 9) Thermocouples; 10) System control; 11) Computer; 12) Electric weight balance. 


\section{Thermocouples}

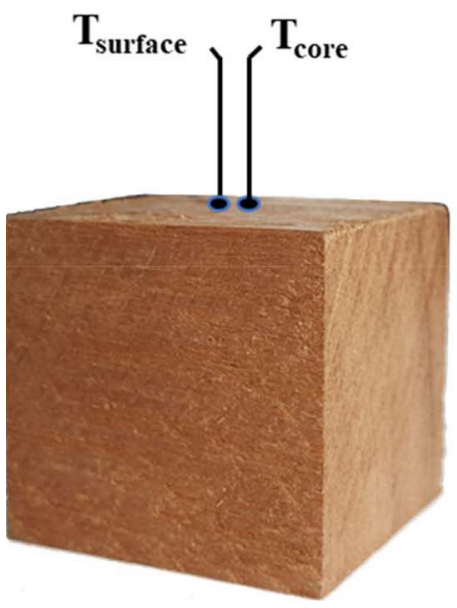

Thermocouples

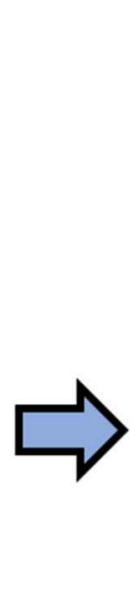

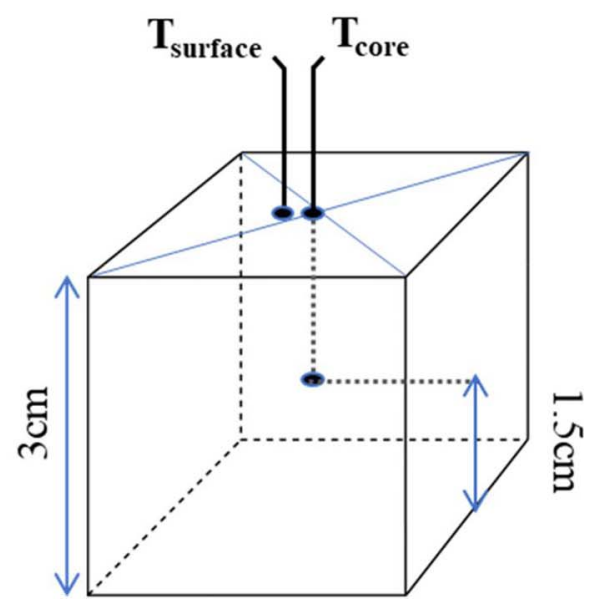

Fig. 3. Positions of the thermocouples in the wood.
The raw material was obtained from a 15-year-old Eucalyptus Grandis tree extracted from Fazenda Água Limpa, University of Brasília property. Wood pieces with roughly the same characteristics (density, size and mass) were cut into $3-\mathrm{cm}$ cubes. The samples were dried in an oven at $105^{\circ} \mathrm{C}$ for $24 \mathrm{~h}$ prior to the experiments. For each experiment, two samples were analysed in each trial run. One sample was coupled to a precision balance to monitor mass loss and another with two thermocouples to monitor the internal and surface temperature (Fig. 3).

Reactor temperature was raised to the temperatures of 250 or $270{ }^{\circ} \mathrm{C}$ by a linear heating rate of $5{ }^{\circ} \mathrm{Cmin}^{-1}$, and held for $60 \mathrm{~min}$ at that temperature in an inert atmosphere $\left(10 \% \mathrm{O}_{2}\right)$. Firstly, the controls experiments were performed without acoustic for both selected temperatures. The other sets of experiments were performed for both temperatures under $1411 \mathrm{~Hz}$ and $2696 \mathrm{~Hz}$ acoustic influence. The chosen frequency was maintained during all the experiment. Five experiments were performed for each condition. The torrefaction treatment parameters are listed in Table 1.

The anhydrous mass $\left(m_{0}\right)$ was determined at the end of the drying process. As the sample is continuously weighed the wood sample thermal decomposition was evaluated in terms of the solid yield $Y_{\text {exp }}(t)$ in (\%) and conversion rate $\alpha$, which was calculated over time for all treatments. The experimental solid yield and conversion rate can then be calculated according to Eq. (1) and Eq. (2) respectively.

$Y_{\text {exp }}(t)=\frac{m_{i}(t)}{m_{0}} \times 100$

$\alpha=\frac{m_{0}-m_{i}(t)}{m_{0}}$

where $m_{i}(t)$ is the mass of the sample during the heat treatment process.

\subsection{Acoustic characterization techniques}

Two experimental techniques were applied to identify which acoustic frequency produced the ideal conditions for maximum particle

Table 1

Torrefaction parameters.

\begin{tabular}{|c|c|c|c|c|c|}
\hline Species & Treatment & Temperature & Dry & Heating rate & Torrefaction time \\
\hline \multirow[t]{3}{*}{$\begin{array}{l}\text { Eucalyptus } \\
\text { grandis }\end{array}$} & $\begin{array}{l}\mathrm{T}_{1}-\mathrm{No} \\
\text { acoustics }\end{array}$ & & $24 \mathrm{~h}$ & $5^{\circ} \mathrm{C} / \mathrm{min}$ & $60 \mathrm{~min}$ \\
\hline & $\begin{array}{l}\mathrm{T}_{2}- \\
1411 \mathrm{~Hz}\end{array}$ & $250^{\circ} \mathrm{C}$ & & & \\
\hline & $\begin{array}{l}\mathrm{T}_{3}- \\
2696 \mathrm{~Hz}\end{array}$ & $270^{\circ} \mathrm{C}$ & & & \\
\hline
\end{tabular}

velocity around the wood sample. As the density of the fluid was known, the optimum conditions were determined by identifying and analysing the shift phase between the two microphones. Due to the relationship between particle velocity and acoustic pressure, the particle velocity is higher when the acoustic gradient pressure signals are in phase opposition [12]. In other words, having higher pressure gradient, higher velocity's is imposed for the particles, creating a condition to perturb the local atmosphere around the wood sample.

For the analysis two microphones were placed side-by-side and faceto-face on both sides of the wood sample and arranged in that configuration for the three spatial axes ( $\mathrm{x}, \mathrm{y}$ and $\mathrm{z}$ ) due to the vectoral characteristics of particle velocity (Fig. 4).

The definition of the distance between the microphones is dependent of the applied acoustic frequency (wave length) and air velocity. A fixed distance of $6 \mathrm{~cm}$ between the microphones was determined taking in to account the calculated wave length for the highest frequency. During the characterization, the wood samples were placed exactly as when the torrefaction experiments were performed. This confers that the obtained values for pressure field consider already the size and location of the sample within the reactor.

For the acoustic experimental procedure, two techniques in the frequency domain (cross-spectrum density) and in time domain (Lissajous curves/Hilbert transform) were applied to the characterization and measurement of the phase shift between microphones.

\subsubsection{Acoustic velocity/pressure formulation}

The acoustic velocity vector $\vec{v}(\vec{x})$ was experimentally determined by processing the acoustic pressure signal measured by the microphones. Using the Euler equation adapted to acoustic processes of small amplitude, the linear inviscid force equation was described as:

$\frac{\partial \vec{v}}{\partial t}=-\frac{1}{\rho} \nabla p$

where, $\vec{v}$ is the acoustic velocity vector field, $p$ the acoustic pressure, and $\rho$ the air density. Assuming the acoustic pressure $p$ and acoustic velocity $\vec{v}$ described as a time harmonic wave:

$p(\vec{x}, t)=P(\vec{x}) \cdot \exp (j \omega t)$

$\vec{v}(\vec{x}, t)=\vec{V}(\vec{x}) \cdot \exp (j \omega t+\Phi)$

where $P(\vec{x})$ and $\vec{V}(\vec{x})$ is the pressure and velocity magnitude of a frequency $\omega$, and phase angle $\Phi$. Then, as a function of frequency $\omega$, the unidimensional linear inviscid force (Eq. (3)) took the following form: 


\section{(a) Side-by-side}

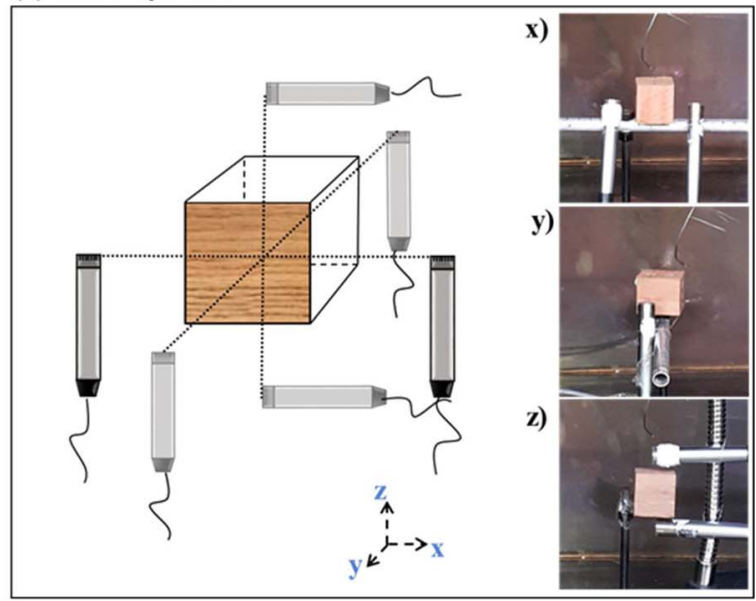

(b) Face-to-face

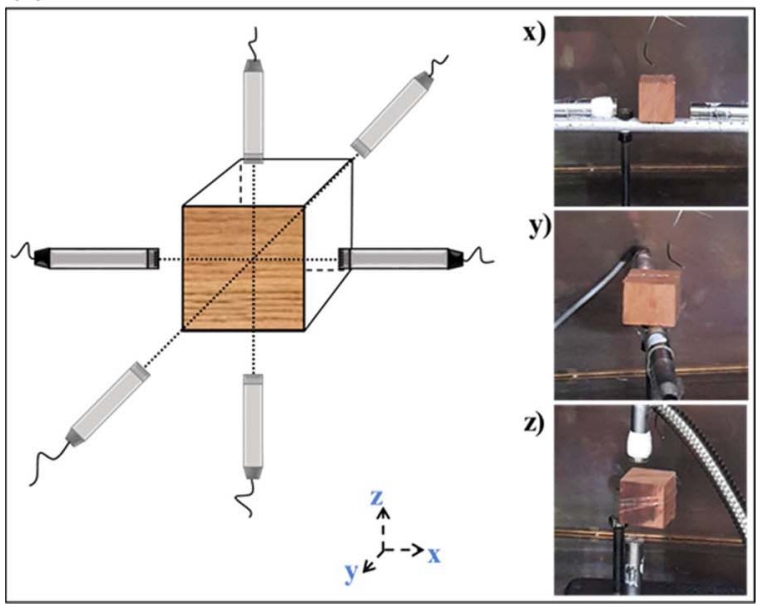

Fig. 4. Acoustic experimental configuration for time (Lissajous/Hilbert) and frequency (Cross Spectrum) domain acoustic characterization.

$\vec{V}(\vec{x})=\frac{j}{\rho \omega} \frac{\partial}{\partial x} P(x) \simeq \frac{j}{\rho \omega} \frac{P(x+\Delta x)-P(x-\Delta x)}{2 \Delta x}=\frac{j}{\rho \omega} \frac{P\left(x_{1}\right)-P\left(x_{2}\right)}{2 \Delta x}$

where, $\Delta x=\left(x_{2}-\vec{x}_{1}\right) / 2$ is the distance between the two microphones in space. The approximative determination of the acoustic velocity field $\vec{V}(\vec{x})$ was made possible by this finite differential approach. The particle velocities for each frequency was obtained from the deviation of the acoustic pressure field $p(\vec{x})$ [12]. A similar technique was used to determine the acoustic intensity for each analysed frequency $[12,13]$.

In the following section, the techniques used to determine the particle velocity around the wood sample are presented. Firstly, the frequency-domain technique (Cross-Spectral Power Density Function), followed by the time-domain techniques (Lissajous curves/Hilbert Transform).

\subsubsection{Frequency domain}

The cross-spectral density function $\hat{S}_{x y}$ was applied to determine the phase shift between the two measured acoustic signals in the frequency domain by the argument Eq. (7):

$\hat{S}_{x y}(f)=\int_{T}^{T} R_{x y}(\tau) \mathrm{e}^{-j 2 \pi f} \mathrm{~d} f=\left|\hat{S}_{x y}\right| \exp \left(-j \phi_{x y}\right)$

where the cross-correlation function $R_{x y}(\tau)$ and phase shift $\phi_{x y}$ between signals $x(t)$ and $y(t)$ is given by Eq. (8) and Eq. (9) respectively.

$R_{x y}(\tau)=\lim _{T \rightarrow \infty} \frac{1}{T} \int_{T / 2}^{T / 2} p(x, t) p(y, t+\tau) d t$ $\phi_{x y}=\arg \hat{S}_{x y}$

\subsubsection{Time domain}

The Lissajous curve, a qualitative technique in the time domain, was applied to determine the phase shift between two microphones [14]. The two microphone acoustic signals $p\left(\vec{x}_{1}, t\right)$ and $p\left(\overrightarrow{x_{2}}, t\right)$ were assumed to be harmonic functions (with excitation frequency $f=\omega / 2 \pi$ in $\mathrm{Hz}$ ):

$p\left(\vec{x}_{1}, t\right)=P\left(\vec{x}_{1}\right) \sin (2 \pi f t)$

$p\left(\vec{x}_{2}, t\right)=P\left(\vec{x}_{2}\right) \sin (2 \pi f t+\phi)$

where, $P\left(\vec{x}_{i}\right)(i=1,2)$ is the acoustic module in a determined position $\vec{x}_{i}$ in space, and $\phi$ the phase shift between the two acoustic signals. The resulting phased harmonic signal acoustic normalization $p\left(\vec{x}_{i}, t\right) / P\left(\vec{x}_{i}\right)(i=1,2)$ had a similar amplitude. For a ratio of 1 , the Lissajous curve was an ellipse, with special cases including circles $\left(P\left(\overrightarrow{x_{1}}\right)=P\left(\overrightarrow{x_{2}}\right)\right.$, and $\left.\omega=\pi / 2\right)$ and lines $(\omega=0)$. The identification by a virtual instrument in Labview of a circle represents a $\omega=\pi / 2$ between the two microphones and a maximum pressure gradient, characterizing maximum particle velocity at the point of interest.

The Hilbert transform of the time signal $x(t)$ is also a time function $\widetilde{x}(t)$ :

$z(t)=x(t)+j \widetilde{x}(t)$

where $z(t)$ is the analytical signal. The Hilbert transform has interesting properties, which enable a few useful applications $[15,16,17,18]$. The Hilbert transform in the time domain was defined by:

$\widetilde{x}(t)=\mathcal{H}[x(t)]=\frac{1}{\pi} \int_{-\infty}^{+\infty} \frac{x(\tau)}{t-\tau} d \tau$

When the damped cosine signal $x(t)$ is analysed, the Hilbert transform $\mathcal{H}[x(t)]$ acts as a quadrature filter, according to Eq. (13). From the complex analytical function $z(t)$ the instantaneous amplitude, instantaneous frequency and instantaneous phase of the signal $z(t)$ could be defined:

$z(t)=x(t)+j \widetilde{x}(t) \rightarrow z(t)=A(t) e^{j \phi(t)}$

The instantaneous amplitude $A(t)$ represents the signal envelope $z(t)$ :

$A(t)=\sqrt{x^{2}(t)+\tilde{x}^{2}(t)}$

and the instantaneous frequency $f(t)$ and signal phase $\phi(t)$ were calculated by:

$f(t)=\frac{1}{2 \pi} \frac{d}{d t}[\phi(t)]$

$\phi(t)=\tan ^{-1}\left(\frac{\widetilde{x}(t)}{x(t)}\right)$

Eq. (16) and Eq. (17) were applied to the present experimental set-up to obtain the phase shift $\phi_{12}$ between two microphone signals:

$p_{1}=p\left(\overrightarrow{x_{1}}, t\right)=P\left(\vec{x}_{1}\right) \sin \left(\omega t+\phi_{1}\right)$

$p_{2}=p\left(\overrightarrow{x_{2}}, t\right)=P\left(\vec{x}_{2}\right) \sin \left(\omega t+\phi_{2}\right)$

$\phi_{12}=\phi_{1}-\phi_{2}$

This result indicated which frequencies produced the highest particle velocity around the wood sample. With the frequencies defined, a decibel meter was used to measure the intensity of the acoustic source inside the reverberant cavity for each identified frequency.

\section{Results and discussion}

The phase spectrum obtained with the different methodologies in the time and frequency domains are compared and validated in Section 3.1. This comparison determined four frequencies and their intensities. 


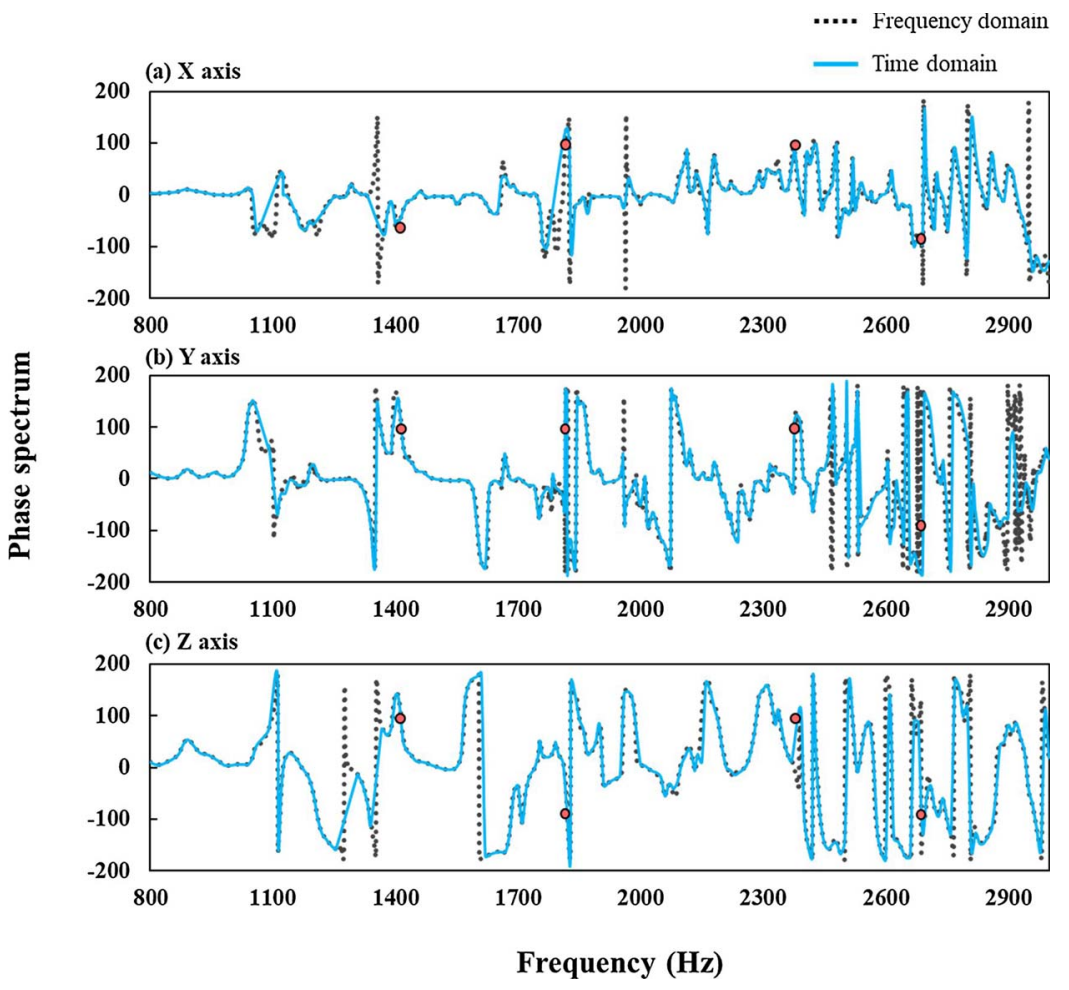

Fig. 5. Time and frequency domain data comparison for the three acoustic techniques with side-by-side microphone configuration.

The preliminary experimental torrefaction results using two selected frequencies are presented and discussed in Section 3.2.

\subsection{Phase spectrum comparison and frequency definition}

A comparison was made between the obtained signal with the crossspectrum technique in the frequency domain and Lissajous/Hilbert transform methods in the time domain. Identification of the desired frequencies that reproduced a phase shift of $\pm 90^{\circ}$ between the two measurement microphones combined with the intensity analysis revealed the acoustic configuration for higher particle velocities around the sample. Fig. 5 illustrates the phase spectrum for the two methodologies versus the frequency.

Three different experimental analyses were performed for each axis due to the vectorial characteristics. The results showed, as expected, different phase spectrum for each direction [12] and an accurate agreement between the two techniques used. The side-by-side microphone arrangement gave better results and agreement than the face-toface configuration.

Frequencies of 1411, 1810, 2478 and $2696 \mathrm{~Hz}$ were identified in both applied techniques and showed an approximate phase shift of \pm $90^{\circ}$ between the microphones in all three spatial axes. An intensity measurement was carried out as displayed in Fig. 6 for the frequencies that showed an approximated phase spectrum behaviour for all cases in the side-by-side configuration.

The identified frequencies were applied to torrefaction experiments with the same parameter conditions with a view to obtaining different results for temperature profiles, solid yield and conversion rate during heat treatment.

\subsection{Experimental acoustic coupling test}

The primary results from a simple investigation of the acoustic field effect on the torrefaction process are presented. The highest and lower identified frequencies $(1411 \mathrm{~Hz}$ and $2696 \mathrm{~Hz})$ were selected for heat treatment test. Fig. 7(a) and (b) shows the evolution of the average temperature at the wood sample surface and core for $250{ }^{\circ} \mathrm{C}$ and $270{ }^{\circ} \mathrm{C}$

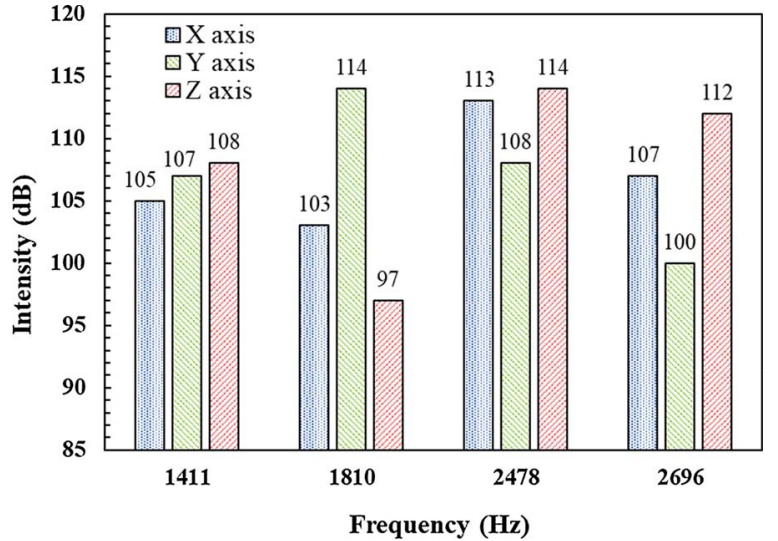

Fig. 6. Intensity values $(\mathrm{dB})$ of the four identified frequencies with side-by-side microphone configuration.

respectively.

As the heat system is controlled by an on/off PID some oscillations were observed on the temperature curves. As expected [2], the temperature at the surface was higher than in the core during the linear heating phase, with and without acoustic frequencies. An inversion of the temperature occurred at treatment temperature due to exothermic reactions inside of the wood sample as identified in $[19,20]$.

Fig. 7 also illustrates a detailed view from temperatures after $230{ }^{\circ} \mathrm{C}$ for (a) and after $250{ }^{\circ} \mathrm{C}$ for (b). It can be seen that there is a modification on temperature profiles for treatments under acoustic. Frequencies mainly affected the core temperatures due to the exothermic reactions.

Indeed, a maximum temperature gradient of $2.3^{\circ} \mathrm{C}$ $\left(270{ }^{\circ} \mathrm{C}-1411 \mathrm{~Hz}\right)$ was observed over the temperature evolution, with and without acoustic. In agreement with literature, the higher the treatment, more evident is the exothermic pic due to exothermic reactions inside of the wood [20]. The heat release effect of this exothermic reactions can be seen as well at the surface temperature when the treatment is performed for the higher temperature of $270{ }^{\circ} \mathrm{C}$ (heat release from the inside of the wood affect the surface temperature). The 
(a) $250^{\circ} \mathrm{C}$

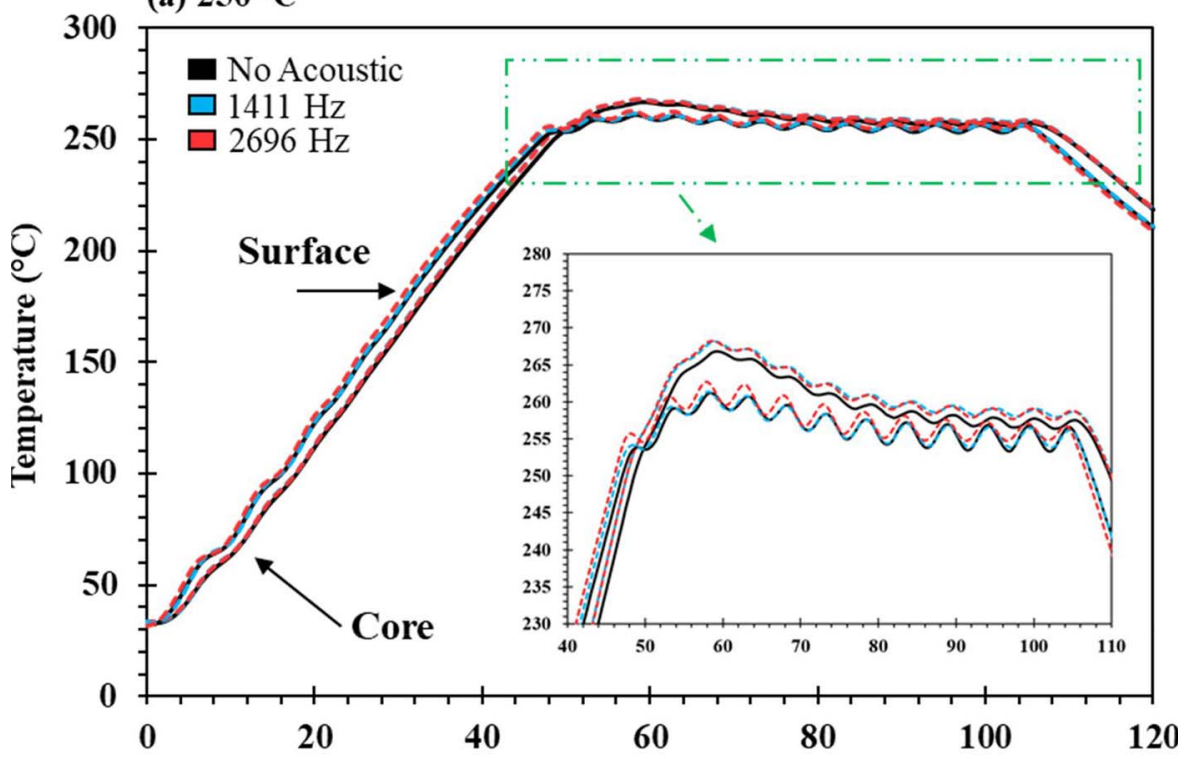

(b) $270^{\circ} \mathrm{C}$

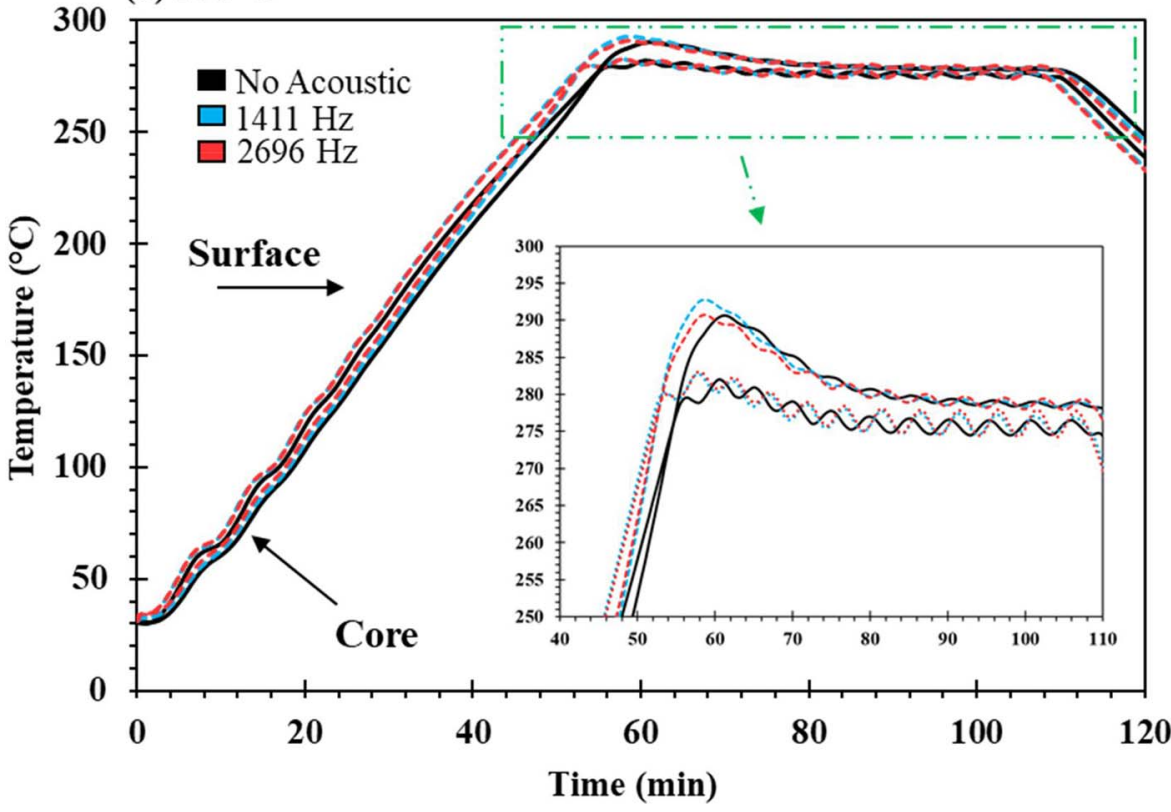

Fig. 7. Average of the surface and core temperature profiles for treatments without acoustic (No Acoustic) and treatments with $1411 \mathrm{~Hz}$ and $2696 \mathrm{~Hz}$ frequencies performed at $250{ }^{\circ} \mathrm{C}$ (a) and $270{ }^{\circ} \mathrm{C}$ (b). Dashed-double-dot arrows indicate the zoomed-in profiles. time taken to reach the treatment temperature level was reduced by $2 \mathrm{~min}$ for $250^{\circ} \mathrm{C}$ and $2.3 \mathrm{~min}$ for $270^{\circ} \mathrm{C}$ treatments.

The effect of the acoustic field combined with the different treatment temperatures was also assessed from the solid yield and conversion rate of the wood samples. Fig. 8 shows the evolution of the solid yield as a function of time along with the differential thermal gravimetry calculated from the derivative of the solid yield curves during time for $250{ }^{\circ} \mathrm{C}$ (a) and $270{ }^{\circ} \mathrm{C}$ (b) treatments.

For the torrefaction experiments without acoustics (continuous black line), wood starts to decompose after $180^{\circ} \mathrm{C}$ as described by [1]. The mass loss increases with increasing temperature and mass loss percentage of $11.5 \%$ for $250{ }^{\circ} \mathrm{C}$ and $18.71 \%$ for $270{ }^{\circ} \mathrm{C}$ obtained for torrefaction without acoustics agree with studies for Eucalyptus grandis at the same conditions $[10,21,22]$. Considering the solid yield profiles for $250{ }^{\circ} \mathrm{C}$ and $270{ }^{\circ} \mathrm{C}$ treatments, an earlier degradation is observed for treatments under $1411 \mathrm{~Hz}$ and $2696 \mathrm{~Hz}$ frequencies.

Solid yield profiles for treatments under acoustic influence has a comparable comportment for both temperatures and shows an interesting shift in time comparable to treatments performed with different heating hates. Similar shifts were reported by [20] for poplar wood under $230^{\circ} \mathrm{C}$ temperature treatment with a heating rate of $1{ }^{\circ} \mathrm{C} \mathrm{min}{ }^{-1}$ and $2{ }^{\circ} \mathrm{C} \mathrm{min}{ }^{-1}$. In fact, the temperature gradient founded in the temperature profiles (Fig. 7) can explain this results for the solid yield.

In both cases under acoustic influence, the tendency revealed an increase in differential thermal gravimetry showing two small peaks in the begging of degradation for $250{ }^{\circ} \mathrm{C}$ and a shift in time showing an earlier degradation for both temperatures. For $250{ }^{\circ} \mathrm{C}$ the peak is less intense compared to $270{ }^{\circ} \mathrm{C}$ peak, showing a stronger degradation for higher temperatures.

The calculated conversion rate $\alpha$ and wood core temperature are illustrated in Fig. 9(a) for $250{ }^{\circ} \mathrm{C}$ and (b) for $270^{\circ} \mathrm{C}$. As the torrefaction process is assumed to start at about $180^{\circ} \mathrm{C}$ [1], the yield at $160^{\circ} \mathrm{C}$ was normalized as the initial yield, and the time was counted as $t=0$ for a better reability of the results.

Resulting values for the conversion rates agree with literature for no 

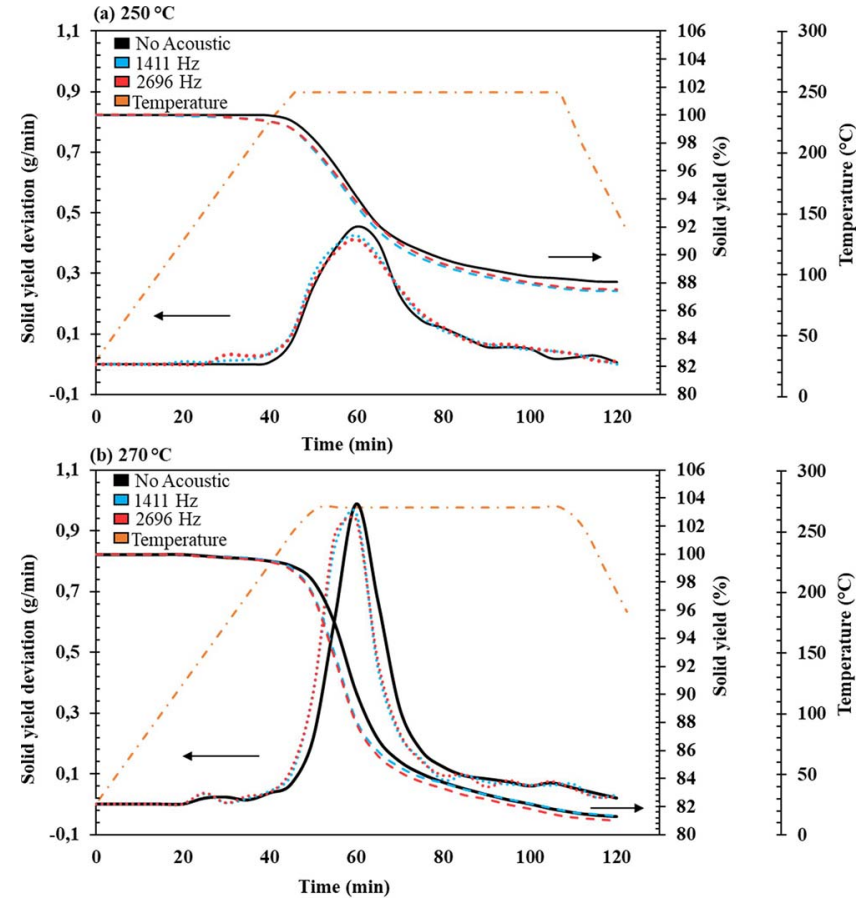

Fig. 8. Solid yield (\%) and solid yield deviation $(\mathrm{g} / \mathrm{min}$ ) for treatments without acoustic (No Acoustic) and treatments with $1411 \mathrm{~Hz}$ and $2696 \mathrm{~Hz}$ frequencies performed at $250{ }^{\circ} \mathrm{C}$ (a) and $270{ }^{\circ} \mathrm{C}(\mathrm{b})$.
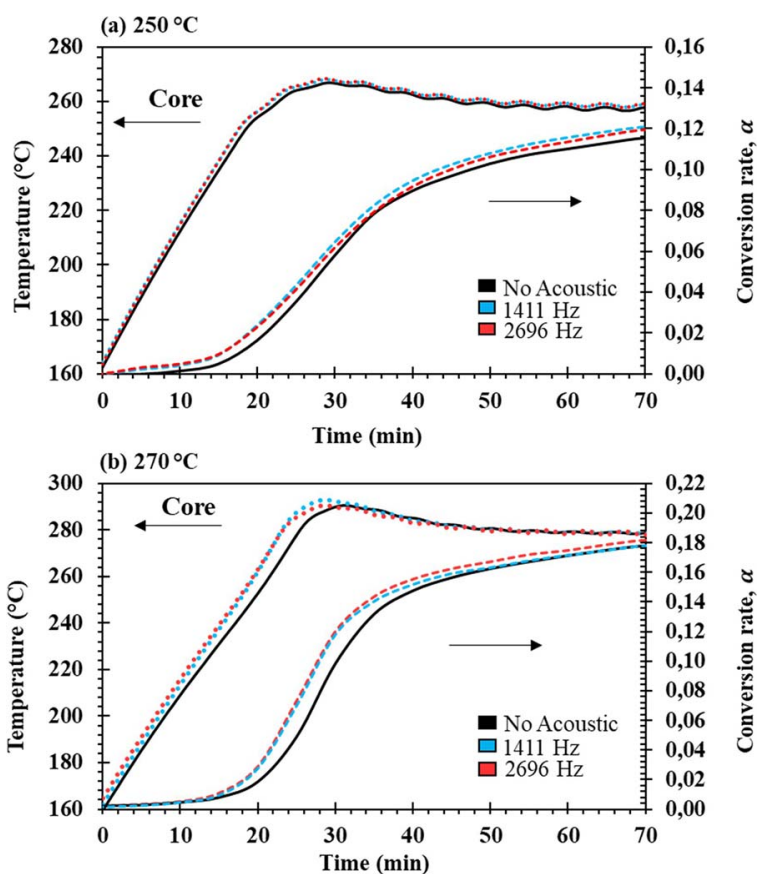

Fig. 9. Conversion rate for treatments without acoustic (No Acoustic) and treatments with $1411 \mathrm{~Hz}$ and $2696 \mathrm{~Hz}$ frequencies performed at $250{ }^{\circ} \mathrm{C}$ (a) and $270{ }^{\circ} \mathrm{C}$ (b).

acoustic treatments at the same conditions [10]. Treatments performed under acoustic shows a noticeable difference compared to the control experiment (no acoustic). Higher conversion rates were obtained for $270{ }^{\circ} \mathrm{C}$ experiments due to the higher temperatures registered inside of the wood.

For a better comparison beetwen treatments with and without acoustic the conversiton rates enhancements were calculated and are illustrated in Fig. 10 for (a) $1411 \mathrm{~Hz}$ and (b) $2696 \mathrm{~Hz}$ treatments. Results shows a similar behaviour for both acoustic treatments an enhancement (a) $1411 \mathrm{~Hz}$

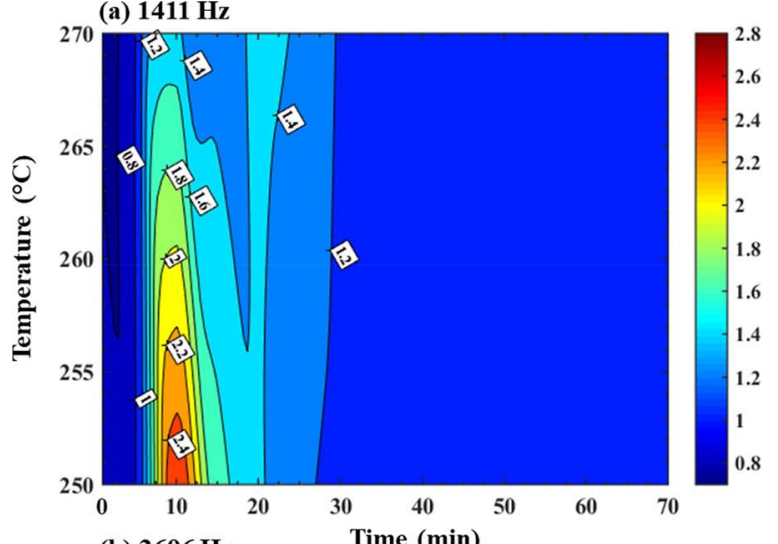

(b) $2696 \mathrm{~Hz}$

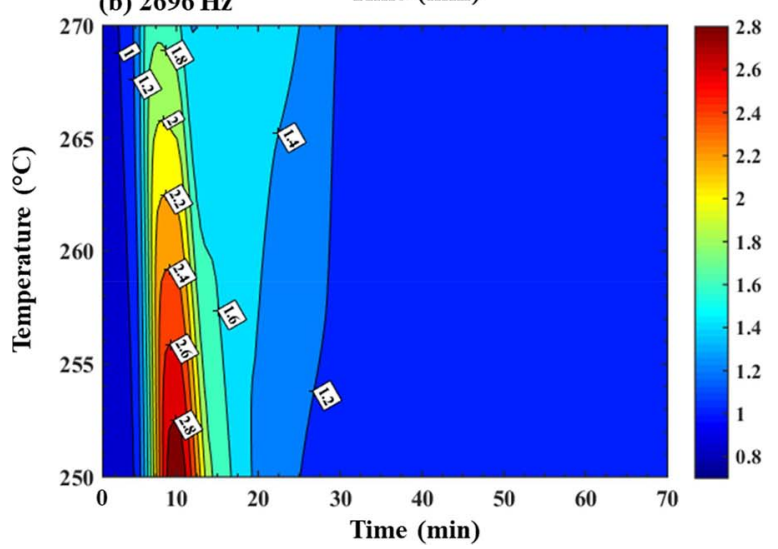

Fig. 10. Calculated conversion rates enhancements for treatments (a) $1411 \mathrm{~Hz}$ and (b) $2696 \mathrm{~Hz}$ performed at $250{ }^{\circ} \mathrm{C}$ and $270{ }^{\circ} \mathrm{C}$.

factors of 2.4 and 2.8 for $250{ }^{\circ} \mathrm{C}$ and $270{ }^{\circ} \mathrm{C}$ respectively. In other words, the conversation rate can be intensified up to $140 \%$ for $250{ }^{\circ} \mathrm{C}$ and 180 $\%$ for $270{ }^{\circ} \mathrm{C}$ in the begging of torrefaction when compared to experiments without acoustic.

As can be noticed in temperature profiles results as well as for the solid yield and conversion rates analysis, the main stage of treatment affected by the acoustic influence was the linear heating and the begging of the settled temperature treatment for both temperatures. Treatment performed under $2696 \mathrm{~Hz}$ were more effective showing a higher modification for temperature profiles and for the solid conversion rates.

An important aspect to pointed out is that the acoustics affected the middle of the torrefaction treatment, showing very similar solid yield for the final products and final temperatures. The results are interesting if the objective of the applied thermal modification is to reduce treatment time. For example, to achieve $10 \%$ of mass loss treatment time was reduce up to $4 \mathrm{~min}$ for $250^{\circ} \mathrm{C}$ and $2.8 \mathrm{~min}$ for $270{ }^{\circ} \mathrm{C}$. Similar patterns and treatment reducing time are reported when torrefaction treatment is performed with different heating rates for standard torrefaction [20].

The hypothesis of the developed work is that the produced acoustic field around the sample can modify the particles velocities around the wood sample and therefore the interaction between resulting volatiles produced by wood degradation (condensable and not condensable). Consequently, the heat and mass transfers can be improved inside the wood due to faster reactions or by convection heat transfer enhancement.

\section{Conclusions}

This paper presented the use of an acoustic system in an existing laboratory torrefaction reactor. The design of the acoustic system is 
detailed. The acoustic behaviour within the reactor was characterized and mapped by applying frequency and time domain methodologies.

Frequencies were explored in the range of $0-3000 \mathrm{~Hz}$ applying both Lissajous/Hilbert techniques in the time domain and the cross-spectrum technique in the frequency domain. The results showed an agreement between the two techniques with identification of higher particle velocities around the wood sample for the following frequencies: 1411, 1810, 2478 and $2696 \mathrm{~Hz}$.

Torrefaction experiments results performed without acoustic showed agreement with literature. A preliminary test was performed applying the frequencies of $1411 \mathrm{~Hz}$ and $2696 \mathrm{~Hz}$ for $250{ }^{\circ} \mathrm{C}$ and $270{ }^{\circ} \mathrm{C}$ temperatures with a heating rate of $5{ }^{\circ} \mathrm{C} \mathrm{min}^{-1}$. Temperature profiles, solid yield evolution and conversion rates enhancement with and without acoustics were investigated. A maximum temperature gradient of $2.3^{\circ} \mathrm{C}$ for $270{ }^{\circ} \mathrm{C}$ was reported for treatment under influence of $1411 \mathrm{~Hz}$. The solid yield profile for $250^{\circ} \mathrm{C}$ and $270{ }^{\circ} \mathrm{C}$ treatment had an earlier degradation for treatments under $1411 \mathrm{~Hz}$ and $2696 \mathrm{~Hz}$ frequencies and showed an interesting shift in time comparable to treatments performed when different heating hates are applied. Considering the conversion rates, noticeable results for the enhancement factors of 2.4 and 2.8 for $250{ }^{\circ} \mathrm{C}$ and $270{ }^{\circ} \mathrm{C}$ respectively were reported.

These results indicate that the acoustic fields affected the interaction between gaseous environment and wood sample affecting heat transfer dynamics under the same experimental conditions. A parametric analysis of biomass torrefaction including acoustic waves will be the subject of further investigations in a forthcoming study.

\section{Acknowledgments}

The research presented was supported by CNPQ and CAPES.

\section{References}

[1] W.-H. Chen, J. Peng, X.T. Bi, A state-of-the-art review of biomass torrefaction, densification and applications, Renew Sustain. Energy Rev. 44 (2015) 847-866, http://dx.doi.org/10.1016/j.rser.2014.12.039.

[2] I. Turner, P. Rousset, R. Rémond, P. Perré, An experimental and theoretical investigation of the thermal treatment of wood (Fagus sylvatica L.) in the range 200-260 ${ }^{\circ} \mathrm{C}$, Int. J. Heat Mass Transf. 53 (2010) 715-725, http://dx.doi.org/10. 1016/j.ijheatmasstransfer.2009.10.020.

[3] E.A. Santos, C.A. Martins, C.L. Nascimento, A new approach to treating pressure oscillations in combustion instability phenomena, Appl. Acoust. 114 (2016) 27-35, http://dx.doi.org/10.1016/j.apacoust.2016.07.006.

[4] E.C. Cintra, B.F.C. Fernandes, Thermoacoustic instabilities of lean disc flames, Fuel 184 (2016) 973-986.

[5] K.I. Matveev, F.E.C. Culick, A study of the transition to instability in a Rijke tube with axial temperature gradient, J. Sound Vib. 264 (2003) 689-706.

[6] S.L. Garrett, TA-1. Thermoacoustic engines and refrigerators, Am. J. Phys. 72 (2004) 11-17.

[7] M. Guédra, F. Bannwart, G. Penelet, P. Lotton, Parameter estimation for the characterization of thermoacoustic stacks and regenerators, Appl. Therm. Eng. 80 (2015) 229-237.

[8] S. Komarov, M. Hirasawa, Enhancement of Gas Phase Heat Transfer by Acoustic Field Application Q 41 (2003), pp. 289-293, http://dx.doi.org/10.1016/S0041624X(02)00454-7.

[9] G.J. Bennett, J. Mahon, D. Murray, T. Persoons, I. Davis, Heat transfer enhancement in ducts due to acoustic excitation, 7th World Conference on Experimental Heat Transfer, Fluid Mechanics and Thermodynamics (ExHFT-7), Krakow, Poland, 28/06 - 03/07, 2009, 200910 http://www.tara.tcd.ie/handle/2262/31586.

[10] P. Rousset, L. Macedo, J.M. Commandré, A. Moreira, Biomass torrefaction under different oxygen concentrations and its effect on the composition of the solid byproduct, J. Anal. Appl. Pyrolysis. 96 (2012) 86-91, http://dx.doi.org/10.1016/j. jaap.2012.03.009.

[11] G.D. Rosseto, Contribution to the Theory and Practice of Experimental Acoustical Modal Analysis, Universidade Estadual de Campinas, 2001 (http://repositorio. unicamp.br/jspui/handle/REPOSIP/265319).

[12] F. Fahy, Sound Intensity, 2nd ed., CRC Press Book, 1995.

[13] S.N. Gerges, Ruídos E Vibrações Veiculares, 1st ed., (2005).

[14] H.A.H. Al-khazali, M.R. Askari, Geometrical and Graphical Representations Analysis of Lissajous Figures in Rotor Dynamic System 2 (2012), pp. 971-978.

[15] J.S. Bendat, A.G. Piersol, Random Data, Analysis and Measurement Procedures, 2nd ed., John Wiley and Sons, New York, 1986.

[16] R.W. Oppenheim, A.V. Schafer, Discrete Time Signal Processing, Prentice Hall, New Jersey, 1989.

[17] M. Feldman, Non-linear system vibration analysis using Hilbert transform-I. Free vibration analysis method Freevib, Mech. Syst. Signal Process. 8 (1994) 119-127.

[18] M. Feldman, Non-linear system vibration analysis using Hilbert transform-II. Forced vibration analysis method Forcevib, Mech. Syst. Signal Process. 8 (1994) 309-318.

[19] P. Rousset, Choix Et Validation Experimentale D'un Modele De Pyrolyse Pour Le Bois Traite Par Haute Temperature: De La Micro-particule Au Bois Massif Patrick Rousset, ENGREF (AgroParis-Tech), 2004 (https://pastel.archives-ouvertes.fr/tel 00106360 ).

[20] M. Chaouch, Effet de l'intensité du traitement sur la composition élémentaire et la durabilité du bois traité thermiquement: développement d'un marqueur de prédiction de la résistance aux champignons basidiomycètes Soutenue, Université Henri Poincaré Spécialité, 2011.

[21] T.O. Rodrigues, P.L.A. Rousset, Effects of torrefction on energy properties of Eucalyptus grandis wood, Cerne 15 (2009) 446-452, http://dx.doi.org/10.1017/ CBO9781107415324.004.

[22] G. Almeida, J.O. Brito, P. Perré, Alterations in energy properties of eucalyptus wood and bark subjected to torrefaction: the potential of mass loss as a synthetic indicator, Bioresour. Technol. 101 (2010) 9778-9784, http://dx.doi.org/10.1016/j. biortech.2010.07.026. 